OPEN ACCESS

Edited by:

Jason D. Shepherd,

University of Utah, USA

Reviewed by:

Inna Slutsky,

Tel Aviv University, Israel

Nicolas Sergeant,

French Institute of Health and Medical

Research (Inserm), France

*Correspondence:

Martin Korte

m.korte@tu-bs.de

Received: 01 November 2016 Accepted: 14 December 2016

Published: 20 January 2017

Citation:

Ludewig S and Korte M (2017) Novel Insights into the Physiological

Function of the APP (Gene) Family and Its Proteolytic Fragments in Synaptic

Plasticity. Front. Mol. Neurosci. 9:161.

doi: 10.3389/fnmol.2016.00161

\section{Novel Insights into the Physiological Function of the APP (Gene) Family and Its Proteolytic Fragments in Synaptic Plasticity}

\author{
Susann Ludewig ${ }^{1}$ and Martin Korte ${ }^{1,2 *}$ \\ ${ }^{1}$ Division of Cellular Neurobiology, Zoological Institute, TU Braunschweig, Braunschweig, Germany, ${ }^{2}$ Helmholtz Centre for \\ Infection Research, AG NIND, Braunschweig, Germany
}

The amyloid precursor protein (APP) is well known to be involved in the pathophysiology of Alzheimer's disease (AD) via its cleavage product amyloid $B(A B)$. However, the physiological role of APP, its various proteolytic products and the amyloid precursor-like proteins 1 and 2 (APLP1/2) are still not fully clarified. Interestingly, it has been shown that learning and memory processes represented by functional and structural changes at synapses are altered in different APP and APLP1/2 mouse mutants. In addition, APP and its fragments are implicated in regulating synaptic strength further reinforcing their modulatory role at the synapse. While APLP2 and APP are functionally redundant, the exclusively CNS expressed APLP1, might have individual roles within the synaptic network. The proteolytic product of non-amyloidogenic APP processing, APPs $\alpha$, emerged as a neurotrophic peptide that facilitates long-term potentiation (LTP) and restores impairments occurring with age. Interestingly, the newly discovered $\eta$-secretase cleavage product, An- $\alpha$ acts in the opposite direction, namely decreasing LTP. In this review we summarize recent findings with emphasis on the physiological role of the APP gene family and its proteolytic products on synaptic function and plasticity, especially during processes of hippocampal LTP. Therefore, we focus on literature that provide electrophysiological data by using different mutant mouse strains either lacking full-length or parts of the APP proteins or that utilized secretase inhibitors as well as secreted APP fragments.

Keywords: amyloid precursor protein, amyloid precursor-like protein, long-term potentiation, synaptic plasticity

\section{INTRODUCTION}

The amyloid precursor protein (APP) gene is localized in humans on chromosome 21 and its expression gives rise to three major isoforms (APP695, APP751, APP770; around $170 \mathrm{kDa}$ ) generated via alternative splicing. APP695 is the predominant isoform in neurons (Robakis et al., 1987; Yoshikai et al., 1990). APP is translated in the endoplasmatic reticulum (ER) where it forms stable dimers which are transported through the secretory pathway via the Golgi apparatus to the cell surface (Isbert et al., 2012; Tan and Evin, 2012). APP is classified as a type I transmembrane glycoprotein with one membrane spanning domain, a large extracellular $\mathrm{N}$-terminus and a small intracellular C-terminus (Dyrks et al., 1988). The mammal APP is part of a larger gene family including the homologs amyloid precursor-like proteins 1 and 2 (APLP1 and APLP2), both of 
which are expressed throughout the body nervous system (brain, spinal cord, retina), immune system (thymus, spleen), muscle (smooth, cardiac, and skeletal), kidney, lung, pancreas, prostate gland, and thyroid gland (Wasco et al., 1993; Liu et al., 2008; Aydin et al., 2012). Interestingly, the APP and APLP2 proteins are found at particularly high levels in the brain where their expression patterns largely overlap in pyramidal neurons of the cortex and hippocampus (Bendotti et al., 1988; Lorent et al., 1995). Thereby, the APP isoform $\mathrm{APP}_{695}$ is especially found in excitatory neurons as well as in GABAergic interneurons while the expression of the other two isoforms, 751 and 770, is assigned to other cell types (Wang et al., 2014; Hick et al., 2015). In vitro studies revealed APP expression in astrocytes and microglia that is increased following brain injury (LeBlanc et al., 1997; Rohan de Silva et al., 1997). On the other hand a more recent study reported that APP expression is restricted to neurons and cannot be found in major glial cells like astrocytes or microglia under basal as well as neuroinflammatory conditions (Guo et al., 2012). These contradictory results are possibly due to the lack of APP specific antibodies. The highly homologous APP family members differ only slightly in their peptide domain structure and hence are displaying a similar proteolytic processing. The relatively short intracellular part of the C-terminus of APP and related proteins contains a YENPTY peptide motif which was shown to promote clathrin mediated endocytosis, modulate $\mathrm{A} \beta$ generation, interfere with $\mathrm{Ca}^{2+}$ homeostasis, and interact with multiple kinases, and adapter proteins (Perez et al., 1999; Leissring et al., 2002; Ring et al., 2007; Jacobsen and Iverfeldt, 2009). The extracellular part of APP is composed of the large E2 and E1 domains containing interaction sites for multiple binding partners like F-spondin, LRP1, Nogo-66 receptor, Notch 2, Netrin, Alcadein, sorL1/LR11, and extracellular matrix components (Müller and Zheng, 2012). Additionally, the E1 domain could be demonstrated to be crucial for the homo- and heterodimerization of APP family members (Soba et al., 2005). Interestingly, the $A \beta$ motive, which is highly conserved in mammals and zebrafish is unique for APP. The APLPs lack this sequence.

Although the structure of both APP and APLPs are well known, the precise cellular function of these proteins remains elusive. For instance, extensive posttranslational modifications and the various cleavage products of APP and APLP processing complicate precise investigations. Nevertheless, several studies assessed putative cellular functions of the APP family members during development and in the adult nervous system (Jacobsen and Iverfeldt, 2009). Certainly, one of the most intriguing discoveries in this respect is the involvement of APP and its cleavage products in processes of synaptic plasticity (Korte et al., 2012) at which activity patterns generated by experience are able to modify neuronal function and structure. These include activity-dependent alterations of the efficacy of synaptic transmission and changes in the structure and number of synaptic connections (for a review see Korte and Schmitz, 2016). Part of the pathophysiology of Alzheimer's disease (AD) is related to the malfunction of synapses (Selkoe, 2002) and the application of amyloid beta (Aß) oligomers has been shown to directly impair synaptic plasticity (Shankar et al., 2008). Despite a huge amount of data which looked at the pathophysiological role of
$A ß$ plaques, it is less clear what the physiological function of APP and its fragments (including $A ß$ ) might be. In addition to APP, it is also important to further the understanding of the putative physiological functions of the related APLP1 and APLP2 proteins and their cleavage products. In this review we concentrate on the role of APP, APLP1, APLP2, and their proteolytic fragments in processes of synaptic transmission and in particular synaptic plasticity under physiological conditions (Table 1).

\section{ROLE OF FULL-LENGTH APP PROTEINS AT THE SYNAPSE}

Gene targeting of APP protein family members provides a powerful tool to investigate the proteins functions. Studying adult APP and APLP2 single KOs in synaptic plasticity revealed only subtle phenotypes (von Koch et al., 1997) mainly due to the overlapping ubiquitous expression of the two proteins in mammals and their similar processing (see Figure 1). Under steady state conditions, the majority of full-length APP is located in the Golgi apparatus and in the trans-Golgi network (Thinakaran and Koo, 2008). When present at the plasma membrane APP and APLPs were shown to form homo- and heterotypic cis interactions and have been proposed to mediate cell-cell interactions in trans (Soba et al., 2005; Kaden et al., 2009; Baumkötter et al., 2012; Mayer et al., 2016). Synaptic adhesion by APP might not only be crucial to build and maintain synaptic contacts, but also to regulate synaptic plasticity (see Figure 2). Highest expression levels at the membrane were observed for APLP1 suggesting that it might be the family member with the upmost potential to mediate cell contacts (Kaden et al., 2009). Recently, the study of Mayer et al. (2016) identified APP and APLP2 to exhibit basal adhesive properties while APLP1 mediated neuronal adhesion is dynamic and regulated by zinc. Copper was instead shown to induce cis- and transdimerization of APP at its E1 domain (Baumkötter et al., 2014). Importantly enhanced trans or cis interaction of APPs or APLPs is accompanied by a reduction of ectodomain shedding of the proteins (Stahl et al., 2014; Mayer et al., 2016) and might therefore interfere with the ability to modulate synaptic function.

\section{APP-KO}

The well-studied constitutive KO of APP in mice leads to an age-related deficit in synaptic plasticity, mainly in long-term potentiation (LTP, see Box 1 for definition). LTP reflects the increase in synaptic strength that lasts for at least $1 \mathrm{~h}$ and is paralleled by alterations at the contact sites between nerve cells, the presynapse (axonal boutons) and postsynapse (dendritic spines). No alterations in synaptic plasticity, the cellular correlate for learning and memory (Stuchlik, 2014) were found in young mice accompanied by normal basal synaptic transmission properties and short-term synaptic plasticity (STP) paralleling the intact behavioral learning of adult and impaired performance of aged mice (Seabrook et al., 1999; Ring et al., 2007; and reviewed by Turner et al., 2003; Korte et al., 2012). The age-dependent LTP defect is further supported by the electrophysiological 
TABLE 1 | Electrophysiological characteristics of the APP protein family members and their proteolytic domains.

\begin{tabular}{|c|c|c|c|}
\hline FL-APP or fragment & Species/Methodic details & Electrophysiological relevant observations & References \\
\hline \multirow[t]{7}{*}{ APPs $\alpha$} & Adult, male Sprague-Dawley rats & (1) Reduction of LTP in DG by up to $50 \%$ in vivo & Taylor et al., 2008 \\
\hline & Intrahippocampal infusion of & $\begin{array}{l}\text { (2.1) Enhancement of LTP at the PP-DG by } 11 \\
\mathrm{~nm} \text { rec APPsa in vivo }\end{array}$ & \\
\hline & (1) Antibodies targeting endogenous APPs $\alpha$ & $\begin{array}{l}\text { (2.2) Increase of NMDA-R EPSC amplitude at } \\
\text { PP-DG by } 0.03 \mathrm{~nm} \text { APPs } \alpha \text { in vitro }\end{array}$ & \\
\hline & $\begin{array}{l}\text { Acute hippocampal slices of Sprague-Dawley rats (young } \\
=3-6 \text { months and aged }=24-27 \text { months) }\end{array}$ & $\begin{array}{l}\text { Increases NMDA-R activation in aged animals } \\
\text { Rescues age-related LTP deficits } \\
\text { No effect on basal synaptic transmission or } \\
\text { glutamate release (PPF) }\end{array}$ & Moreno et al., 2015 \\
\hline & $\begin{array}{l}\text { Exogenous, recombinant APPs } \alpha \text { application } \\
(0.1-1-10 \mathrm{~nm})\end{array}$ & $\begin{array}{l}\text { Dose-dependent increase of NMDA-R } \\
\text { related } I_{S E}\end{array}$ & \\
\hline & $\begin{array}{l}\text { Acute hippocampal slices of adult, APP/APLP2 } \\
\text { conditional DKO mice }\end{array}$ & Rescue of impaired LTP & Hick et al., 2015 \\
\hline & Bath application of recombinant APPs $\alpha(10 \mathrm{~nm})$ & No effect on basal synaptic transmission & \\
\hline \multirow[t]{2}{*}{ APPSB } & $\begin{array}{l}\text { Acute hippocampal slices of adult, APP/APLP2 } \\
\text { conditional DKO mice }\end{array}$ & No rescue of impaired LTP & Hick et al., 2015 \\
\hline & Bath application of recombinant APPsB (50 nm) & No effect on basal synaptic transmission & \\
\hline \multirow[t]{2}{*}{ AB1-15 } & Acute hippocampal slices of adult, c57bl6 mice & fM Aß1-15 enhances PTP and LTP & Lawrence et al., 2014 \\
\hline & Bath application of aß1-15 (50 fM, $50 \mathrm{pM})$ & pM Aß1-15 has no effect on PTP or LTP & \\
\hline \multirow[t]{3}{*}{$\begin{array}{l}\text { APP-JCasp domain }\left(\mathrm{NH}_{2}\right. \\
\text { terminal region of APP) }\end{array}$} & $\begin{array}{l}\text { Intracellular delivered to presynaptic terminals of acute } \\
\text { hippocampal slices of adult WT and APP KO mice }\end{array}$ & $\begin{array}{l}\text { Strong reduction in basal synaptic transmission } \\
\text { in WT, not in APP KO }\end{array}$ & Fanutza et al., 2015 \\
\hline & & $\begin{array}{l}\text { Increases PPF and synaptic frequency } \\
\text { facilitation in WT, not in APP KO }\end{array}$ & \\
\hline & & $\begin{array}{l}\text { Reduction of the rate of vesicle depletion } \\
\text { without affecting vesicle recycling }\end{array}$ & \\
\hline AICD & $\begin{array}{l}\text { Acute hippocampal slices of APP } \triangle \text { CT15/APLP2-DM: } \\
\text { mice lacking the last } 15 \text { amino acids of APP including } \\
\text { YENPTY motif and APLP2 }\end{array}$ & $\begin{array}{l}\text { Decreased potentiation during PTP and LTP } \\
\text { Trend toward decreased L-LTP } \\
\text { Increased basal synaptic transmission } \\
\text { Unaltered PPF and STP }\end{array}$ & Klevanski et al., 2015 \\
\hline \multirow[t]{2}{*}{ APP } & Murine OHCs of PO APP-KO mice & No difference in $1 / O$ characteristic & Weyer et al., 2014 \\
\hline & & Unaltered short term plasticity & \\
\hline \multirow[t]{4}{*}{ APLP1 } & APLP1-deficient adult male mice & In vivo recording at PP-GC synapse: & Vnencak et al., 2015 \\
\hline & & Enhanced excitatory transmission & \\
\hline & & $\begin{array}{l}\text { Decreased paired pulse inhibition of population } \\
\text { spikes (decreased network inhibition) }\end{array}$ & \\
\hline & & Unchanged STP and LTP & \\
\hline
\end{tabular}


TABLE 1 | Continued

\begin{tabular}{|c|c|c|c|}
\hline FL-APP or fragment & Species/Methodic details & Electrophysiological relevant observations & References \\
\hline \multirow[t]{3}{*}{ APLP2 } & $\begin{array}{l}\text { Acute hippocampal slices of young (1-2 months) and } \\
\text { aged (10-12 months) APLP2 deficient mice }\end{array}$ & $\begin{array}{l}\text { Unchanged input-output characteristics across } \\
\text { ages to controls }\end{array}$ & Midthune et al., 2012 \\
\hline & & Unaffected PPF remains & \\
\hline & & No alterations in LTP & \\
\hline
\end{tabular}

APP/APLP2 Acute hippocampal slices of conditional adult DKO mice

Pronounced deficit in induction and maintenance of LTP

Impaired PPF

Unaltered basal synaptic transmission

Unchanged spontaneous synaptic mEPSCS

in CA1

No differences in NMDA-r subunit composition

Acute hippocampal slices of 16-24 days old conventional DKO mice

Increased PPF and synaptic frequency

facilitation

Decreased mEPSCs frequency and increased MEPSC decay time

(1) Unaltered basic synaptic transmission

Prox et al., 2013 impaired short-term synaptic plasticity strongly impaired LTP
Fanutza et al., 2015

Hick et al., 2015
(2) In vivo hippocampal recordings in adult male CKO

mice

(1) Acute hippocampal slices of adult, female, conditional adam- $10 \mathrm{KO}$ 

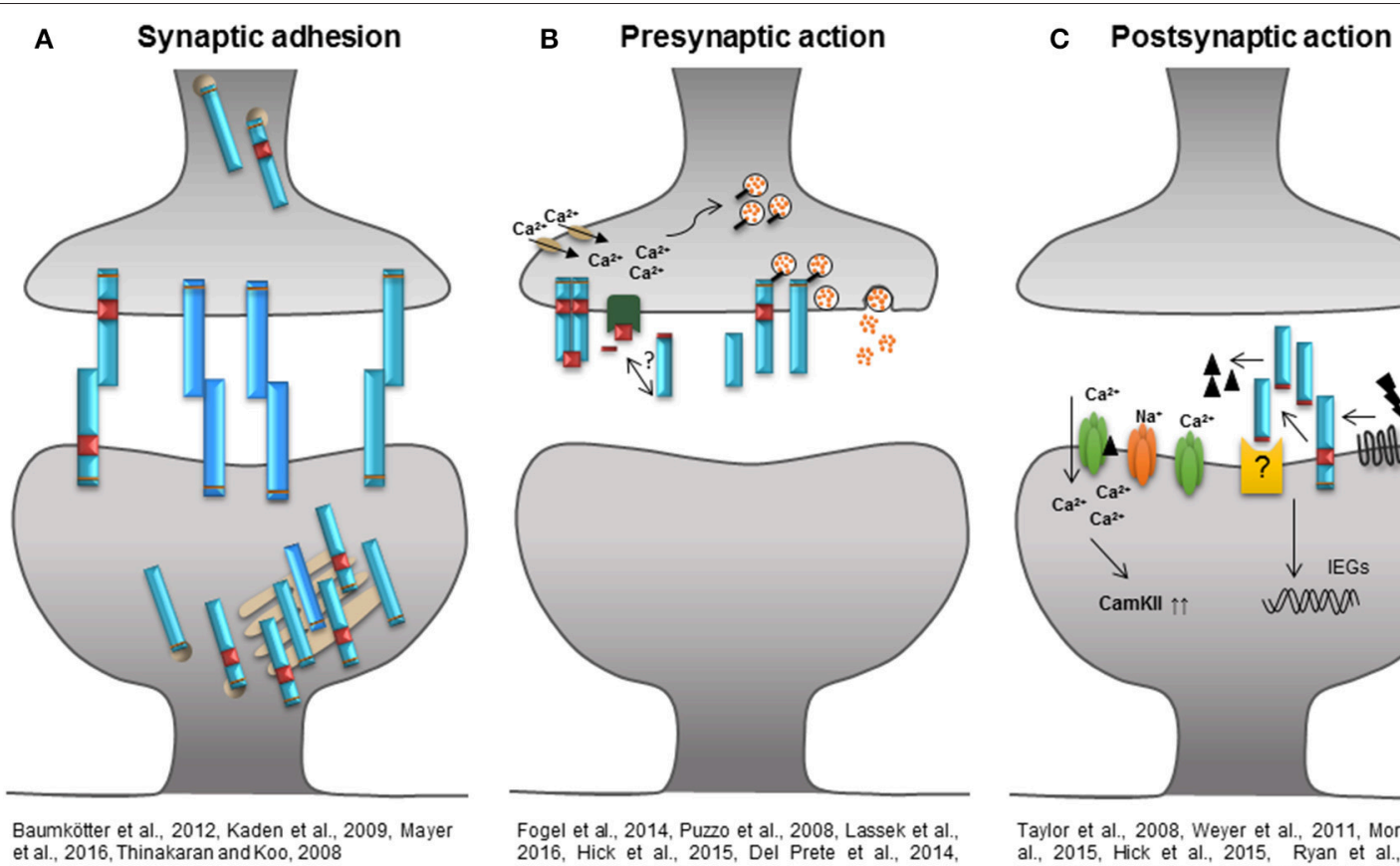

Fogel et al., 2014, Puzzo et al., 2008, Lassek et al., Fogel et al., 2014, Puzzo et al., 2008, Lassek et al.,
2016, Hick et al., 2015, Del Prete et al., 2014, Fanutza et al., 2015
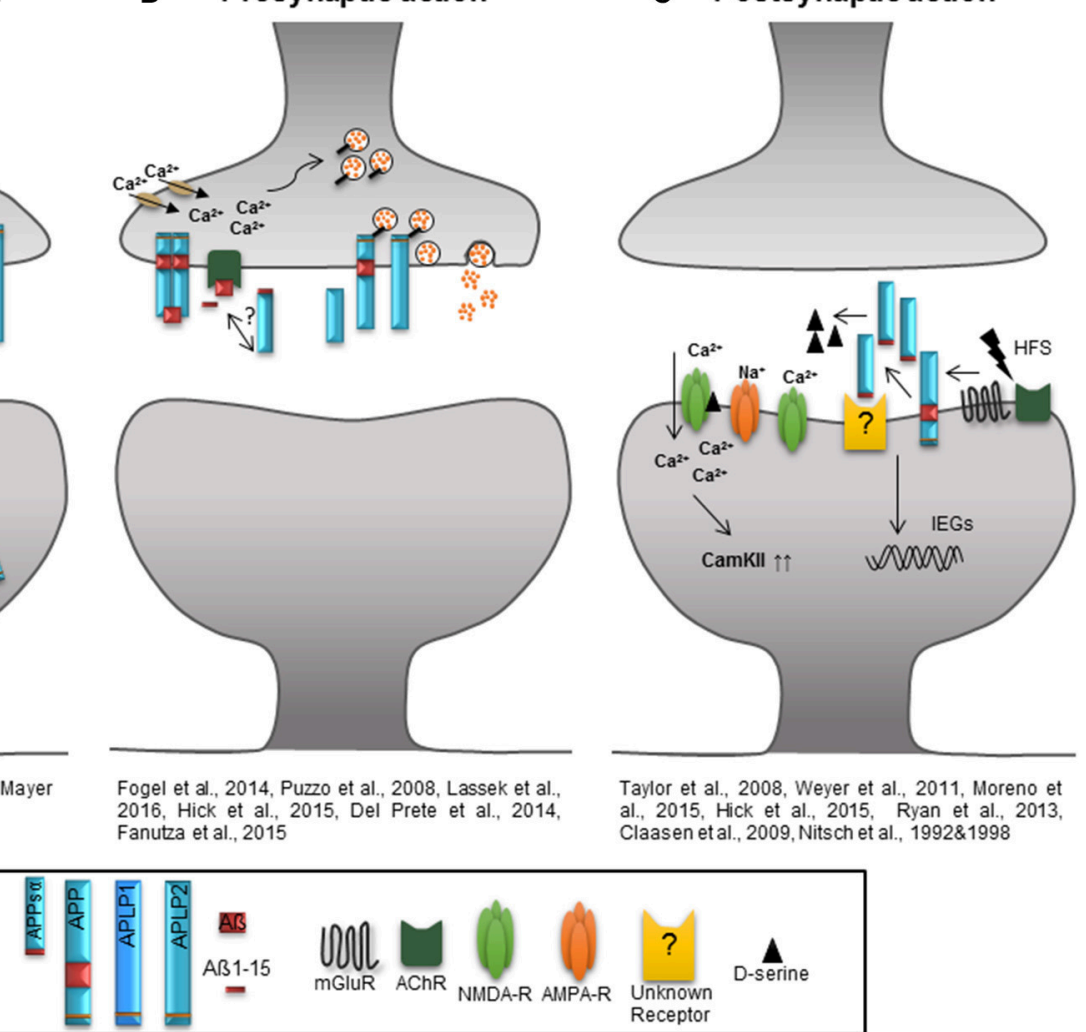

FIGURE 2 | Role of the APP protein family at the synapse. (A) The extracellular domains of APP/APLPs mediate cell-cell adhesion in trans supporting synaptic connectivity. APP and APLP2 are mainly located in the Golgi apparatus and trans Golgi network. When integrated in the plasma membrane, APP and APLP2 show basal adhesive characteristics, while the proportion of plasma membrane APLP1 is higher and it's insertion dynamic. (B) Homodimerized APP might function as a cell-surface G-protein coupled receptor which is recognized by $A B$ and initiates signaling as well as neurotransmitter release by activation of calcium channels. $A B$, AB1-15, and potential also APPs $\alpha$ induce an AChR-dependent signal facilitating glutamate release via an increase in presynaptic calcium concentration. APP and APLP2 are mainly implicated in presynaptic function and their intracellular domains are associated with proteins of the synaptic vesicle release machinery regulating the vesicle content in the presynaptic active zone. (C) High frequency stimulation increases APP ectodomain shedding that might be linked to the activation of mGluRs or AChRs. High amounts of APPs $\alpha$ facilitate the function of NMDA-Rs by increasing the agonist D-serine or by induction of immediate early genes as well as signaling pathways like that of CamKIl to support synaptic plasticity.

measurements of murine organotypic hippocampal slice cultures (OHCs) from APP-KO pups prepared at postnatal day zero. No differences in the Input-Output characteristics and STP of APP-KO in comparison to wild-type OHCs were observed (Weyer et al., 2014). In agreement, the loss of APP does not impair synaptic plasticity in the adult organism and thereby APLP2 and maybe APLP1 are considered to perform redundant functions, but fail to compensate for APP deficiency with age.

\section{APLP2-KO}

The function of APLP2 in synaptic plasticity has also been addressed in detail since this protein shares the highest degree of sequence homology with APP within the gene family. Furthermore, the spatial and temporal expression pattern of APLP2 is highly reminiscent to that of APP (Wasco et al., 1993). APP and APLP2 are ubiquitously expressed in the nervous tissue and at the neuromuscular junction (NMJ, Slunt et al., 1994; Lorent et al., 1995) as well as in pyramidal and GABAergic neurons of the hippocampus and cortex (Wang et al., 2014; Hick et al., 2015). In contrast to APP-KO mice, young and aged APLP2 single KOs behave like wild-type mice showing no impairments in LTP, STP, PPF, or basal synaptic transmission (Weyer et al., 2011; Midthune et al., 2012). These observations go in line with normal learning and memory performance in cognitive tasks like the Morris-Water-Maze (MWM) or the passive avoidance test (Heber et al., 2000; Guo et al., 2012). The functional effects are consistent with investigations of dendritic spine numbers at excitatory neurons, reflecting the number of excitatory synapses. Whereas, the spine density assessed in vivo was affected in aged APP-KO animals, it was unaltered in APLP2-KO mice as well as in APLP2 OHCs in vitro (Lee et al., 2010; Midthune et al., 2012; Weyer et al., 2014). It seems likely that endogenous APP is able to compensate for the genetic ablation of APLP2 with age, while vice versa APLP2 is incapable to compensate the loss of APP in aged animals. This implicates that APP has either different or dominant neuronal functions compared to APLP2. 


\begin{abstract}
BOX 1 | Term definitions.
Synaptic plasticity designates the activity-dependent alterations of the efficacy of synaptic transmission and changes in the structure as well as number of synaptic connections whereby activity patterns are generated by experience. Synaptic connections build the contact sites between nerve cells and alterations at these contact sites provide the basis to store memories and information within neuronal networks (Korte and Schmitz, 2016).

LTP_Long-term potentiation is defined as a persistent increase in synaptic strength lasting for at least $1 \mathrm{~h}$ (Bliss and Lomo, 1973). It consists of an induction phase, including processes that trigger the alterations leading to the changes in synaptic efficacy followed by the expression or maintenance phase of LTP. LTP can be divided in different types: LTP lasting from 1 to $3 \mathrm{~h}$ is independent of transcription and translation and named early or E-LTP; if it lasts longer than $3 \mathrm{~h}$, it is generally dependent on altered gene expression and referred to as late LTP (L-LTP, Bliss and Collingridge, 1993; Kandel, 2001).

LTD-Long-term depression is the counterpart of LTP and therefore defined as a persistent reduction in synaptic strength. LTD prevents excessive synaptic activity (Korte and Schmitz, 2016).

STP-Short term synaptic plasticity is a form of synaptic plasticity that is NMDA-R dependent, but presynaptically expressed. It depends on the frequency of induction as well as subsequent activity and lasts from ms to min (Zucker and Regehr, 2002; Volianskis and Jensen, 2003).

PPF-Paired-pulse facilitation is a NMDA receptor-independent form of short-term plasticity and a typical presynaptic phenomenon. The facilitation is caused in the process of re-establishment of intracellular $\mathrm{Ca}^{2+}$ levels after repetitive $\mathrm{Ca}^{2+}$ influx into the presynaptic terminal. PPF can be investigated by applying two single stimuli spaced by a defined time interval. Depending on the length of the Inter-Stimulus-Interval and type of stimulus used the second signal is facilitated or depressed (Paired-pulse depression, PPD). At shorter ISIs of <20 ms PPD is observed whereas larger ISls > 20 ms lead to PPF (Zucker and Regehr, 2002).

Spine density-Spines are small membrane protrusions from dendrites often with a neck-head structure building the postsynaptic elements of glutamatergic synapses (Korte and Schmitz, 2016). Their density can therefore be seen as correlate of the amount of excitatory synapses and often represents functional changes in synaptic strength.
\end{abstract}

\section{APLP1-KO}

Despite the generation and first characterization of the conventional APLP1-KO mouse in 2000 by Heber and colleagues, the function of this homolog has been less attended in synaptic plasticity Since APLP1 is the only APP family member with restricted expression to the brain (Lorent et al., 1995; Thinakaran and Koo, 2008; Klevanski et al., 2014), it is intriguing to speculate that APLP1 has a unique neuronal role and therefore might also be of particular importance for synaptic plasticity. However, Heber et al. (2000) described only minor (if any) distinct phenotypes of APLP1-KO. The ablation of the APLP1 gene function did not result in impaired cognitive behavioral performance in the MWM task but rather. However, during the behavioral paradigm it has been noted that depletion of APLP1 resulted in an improvement of acquisition learning. The in vivo analysis at the perforant path-granule cell synapse (PPDG) in young adult mice (16-20 weeks old) revealed unaltered STP and LTP, associated to enhanced excitatory transmission (Vnencak et al., 2015). The authors argued that maybe a larger number of perforant path synapses or an increased synaptic strength in APLP1-deficient mice may cause this enhancement, but final clarification is missing. Furthermore, the paired-pulseinhibition (PPD) paradigm of the population spike points toward decreased GABAergic network inhibition in APLP1-KOs, an effect observed also for other APP-KO models.

\section{ROLE OF THE APP PROTEIN FAMILY IN SYNAPTIC INHIBITION}

The hippocampus is comprised of 95\% excitatory and 5\% inhibitory neurons, both expressing the APP family proteins (Hick et al., 2015). It is well established that the GABAergic system is especially important during the induction of LTP (Bliss and Lomo, 1973) and that excitation and inhibition must be tightly balanced for a well-coordinated network. This notion is supported by the finding that the inhibition of $\mathrm{GABA}_{\mathrm{A}}$ receptors facilitates LTP and leads to hyperexcitability causing epileptic seizures (Gustafsson and Wigström, 1988; Casasola et al., 2004). Hippocampal hyperactivity is a hallmark of neurological diseases like mild cognitive (MCI, Bakker et al., 2012) and AD (Palop et al., 2007). Several studies suggest that the hyperactivity is caused by APP overexpression (Born et al., 2014) while others assume $A ß$ to be the trigger (Busche et al., 2008; Minkeviciene et al., 2009). The APP family proteins seem to be closely involved in regulating GABAergic transmission as both APLP1-KO and aged APP-KO mice exhibit reduced GABAergic mediated PPD responses (Seabrook et al., 1999; Vnencak et al., 2015) and in addition increased susceptibility for kainite-induced seizures (Steinbach et al., 1998). Moreover, supporting the role of APP within the GABAergic network are the chronic reduction of $G_{A B A}$ receptors and the lowered number of $G_{A B A}$ autoreceptors mediating PPD of inhibition in the absence of APP (Fitzjohn et al., 2000) as well as the identified interaction of APP with $\mathrm{GABA}_{B}$ receptors in vitro (Norstrom et al., 2010) as well as recently in vivo (Schwenk et al., 2016). Like in APP-KO, in mice expressing only the secreted APPs $\alpha$ on an APLP2 deficient background (APPsa-DM; Weyer et al., 2011), the neutralization of $\mathrm{GABA}_{\mathrm{A}}$ receptors by picrotoxin rescues impaired LTP presumably due to a facilitation of postsynaptic depolarization. Moreover, while addressing oscillatory activity by recording local field potentials (LFPs) in the dorsal hippocampus revealed normal theta- and gamma-frequency bands the coupling of gamma amplitude to the theta phase was diminished in around 9 months old APP-KO mice (Zhang et al., 2016). This observation indicates the presence of alterations within the local inhibitory networks (Zhang et al., 2016) thereby preventing a coordinated neuronal communication. Investigations by Yang et al. (2009) yielded that deletion of APP in hippocampal neurons increased L-type voltage gated $\mathrm{Ca}^{2+}$ channel (LTCC) levels and function underlying an altered GABAergic STP. Likewise, a recent report implied APP possibly via the APPs $\alpha$ fragment to stabilize $\mathrm{Ca}^{2+}$ homeostasis by regulating inhibition of LTCCs (Hefter et al., 2016). Nevertheless, APLP1 deficiency causes no LTP deficit even though GABAergic inhibition is affected in APLP1-KO mice. The related proteins, APP and APLP2, might 
exhibit similar interactions at the presynaptic membrane and thus possibly compensate for the functional loss of APLP1 at the postsynaptic density (PSD) during LTP induction and maintenance.

\section{APP AND APLP2 DOUBLE KO}

The high content of APP and APLP2 especially in pyramidal cells of the cortex and hippocampus (Lorent et al., 1995) and their localization at synaptic sites (Laßek et al., 2013) suggest a role in synaptic transmission and synaptic plasticity. To address the function of these redundantly expressed proteins, combined $\mathrm{KO}$ models are necessary. Unfortunately, APP and APLP2 double KO (DKO) mice die perinatally (von Koch et al., 1997; Heber et al., 2000) indicating an indispensable role for both these proteins during development. The lethal phenotype of these DKO mice is most likely due to important functions of APP and APLP2 at the NMJ (Wang et al., 2005; Weyer et al., 2011) and reviewed by Caldwell et al. (2013). Neuromuscular transmission is severely impaired due to a reduced amount of synaptic vesicles and their impaired release. While the KnockIn of APPs $\alpha$ in the APP/APLP2-DKO mouse (APPs $\alpha-D M$ ) rescued the lethal phenotype it resulted in muscular weakness and severe alterations in NMJ morphology (Ring et al., 2007). While the above study indicated that at the NMJ of APP and APLP2 DKO mice most alterations are found presynaptically, the role of the APP family members and their fragments at synapses within the CNS still remained open. The conditional approach used by Hick et al. (2015) opened the possibility to address the function of APP and APLP2 in the CNS leaving the PNS unaffected. Crossing of APP flox/flox on an APLP2 null background to NexCre-deleter mice generates viable double mutants (cDKO). In these mice the depletion of APP is initiated from embryonic stage 11.5 onwards in excitatory neurons of the forebrain, while APLP2 is constitutively not expressed allowing the investigation of neurodevelopmental effects. Young adult mice show a pronounced deficit in LTP induction and maintenance as well as impairments in PPF. Alterations during the initial phase of LTP, the so-called post-tetanic potentiation and also STP provided a hint toward an impaired presynaptic function. In contrast, the functionality of the postsynapse remained unaffected as basal synaptic transmission was unaltered (Hick et al., 2015). Another study using young conventional APP/APLP2 deficient mice (APP/APLP2-DKO, surviving escape mutants) described increased PPF and synaptic frequency facilitation (FF, Fanutza et al., 2015), supporting the assumption that APP and APLP2 are involved in presynaptic function.

\section{PRESYNAPTIC FUNCTION OF APP FAMILY PROTEINS}

Short-term plasticity (STP) depends on the release probability of synaptic vesicles, their recycling and content in the presynapse as well as on the activity of calcium sensor kinases. APP and APLP2 show a variety of possible interactions with the synaptic vesicle release machinery: Biochemical approaches showed that APP is associated with synaptic vesicle proteins (Del Prete et al., 2014; Laßek et al., 2014) and that it can be cleaved within vesicles by BACE-1 (Del Prete et al., 2014). Especially the intracellular regions of APP, APLP2, and CTF- $\beta$ have been shown to interact with presynaptic vesicle proteins like Rab, AP-2 subunits, the $\mathrm{Ca}^{2+}$ sensors synaptotagmins, clathrin, and complexin (Del Prete et al., 2014; Fanutza et al., 2015). Results from APP-KO animals point toward a role of APP in controlling synaptic vesicle protein content in the presynaptic active zone as synaptophysin, synaptotagmin-1, and SV2A protein levels are reduced in APP KO mice. In contrast, when beside APP also APLP1 or APLP2 are gene targeted, the abundance of synaptic vesicle proteins is increased (Laßek et al., 2014). The increase in SV2A and synaptotagmin-1 has also been observed in the conditional APP/APLP2 mutant mice generated by Hick et al. (2015) and recently analyzed (Laßek et al., 2016). In that study, Lassek and colleagues further show that APP deletion disturbs $\mathrm{Ca}^{2+}$ homeostasis, due to a misregulation of calmodulin and neuromodulin but not of the expression of CaMKII or $\mathrm{Ca}^{2+}$ channels. APLP1 is also localized at the presynaptic active zone (Laßek et al., 2016), but beside the function as mediator of neuronal adhesion (Kaden et al., 2009; Mayer et al., 2016) and its potential involvement in GABAergic neurotransmission (Vnencak et al., 2015) no other role or interaction partners have been attributed so far.

\section{POSTSYNAPTIC FUNCTION OF APP FAMILY PROTEINS}

In addition to a possible function at the presynapse in the developing and mature CNS, all APP family members have been suggested to play a role at the postsynapse. In particular an interaction with $\mathrm{N}$-methyl-D-aspartate receptors (NMDA$\mathrm{R})$ has been shown especially for the GluN1/GluN2A and GluN1/GluN2B subunits (Cousins et al., 2015). APP, APLP1, and APLP2 are further involved in the regulation of the cell surface expression of NMDA-Rs thus controlling NMDA-R homeostasis (Cousins et al., 2015).

Addressing the role of APP and APLP2 at the postsynapse with the whole cell patch clamp method (measuring miniature excitatory postsynaptic currents (mEPSCs) yielded conflicting results. The study of Fanutza et al. (2015) using conventional APP/APLP2 double mutants, described a decreased mEPSC frequency and an increased mEPSC decay time leading to the assumption of redundant mediated function of APP and APLP2. In contrast, Hick et al. (2015) investigated a conditional APP/APLP2 KO (cDKO) and found no alterations in spontaneous synaptic mEPSCs and in their frequencies. Moreover, the analysis of the NMDA-R subunit composition further points toward unchanged postsynaptic transmission in the cDKO mice (Hick et al., 2015). In this context it is important to note that around $80 \%$ of the APLP2 ${ }^{-/-} \mathrm{APP}^{-/-}$ mice die within the first weeks after birth and only $0.3 \%$ survive until weaning (von Koch et al., 1997; Heber et al., 2000). Therefore, the mice studied by Fanutza et al. (2015) 
were so called "escape-mutants" and their results need to be interpreted with care. It might be that the surviving conventional DKOs developed adaptation mechanisms e.g., an upregulation of synaptic proteins accounts for these controversial results. APLP1 is supposed to accumulate at the postsynapse (Kim et al., 1995) and was also shown to regulate NMDA-R content (Cousins et al., 2015). APLP1, like the other two family members contains the highly conserved YENPTY interaction motif and in thus able to initiate downstream signaling cascades in the postsynaptic compartment supporting synaptic plasticity (activation of intracellular signaling cascades and their contribution to synaptic plasticity is discussed below).

\section{PROTEOLYTICALLY GENERATED PEPTIDES-APPS $\alpha, A P P S \beta, A \beta, A N-\alpha$, AN-B}

Gene targeting of APP family members using single and double mutants provided evidence about the possible involvement of these proteins in synaptic plasticity, but it could not answer the question of whether the observed effects arose from the action of the full-length proteins or from the absence of their secreted fragment(s).

Evidence pointing to a role of APP fragments in processes of synaptic plasticity arose from the observation that APP processing by $\alpha$ - and $\beta$-secretase is activity-dependent (Nitsch et al., 1993; Fazeli et al., 1994; Kamenetz et al., 2003; Gakhar-Koppole et al., 2008) and can thus be potentiated by neuronal depolarization or high frequency stimulation (HFS). Consequently, the released domains may be especially involved during processes of synaptic activity.

Depending on their site of release, extra- and/or intracellularly, they might have functions as signaling molecules or initiate signaling by binding to different types of receptors. Proteolytic processing of APP is depicted in Figure 1 and was shown to be similar for APLP1 and APLP2 except for the release of $A B$ as its coding sequence is absent in the APP homologs (Eggert et al., 2004; Walsh et al., 2007). The current view allows differentiation between three different pathways initiated by the $\alpha-, \beta$-, or $\eta$-secretase (see Figure 1). In the non-amyloidogenic pathway the $\alpha$-secretase cuts within the $A \beta$ domain liberating the large APPs $\alpha$ ectodomain and a membrane-anchored C-terminal fragment $\alpha(\mathrm{CTF} \alpha)$. The latter is further cut by the $\gamma$-secretase releasing the p3 fragment extracellularly and the remaining APP intracellular domain (AICD) into the cytoplasm. The amyloidogenic processing by the $ß$-secretase yields the APPsß ectodomain and the membrane-tethered CTF $B$. Afterwards the activity of the $\gamma$-secretase generates the AICD peptide along with Aß. Recently Willem et al. (2015) identified a $\eta$-secretase cleavage site in the extracellular domain of APP releasing a short extracellular APPs $\eta$ ectodomain. Subsequent processing of the remaining membrane anchored CTF $\eta$ by the $\alpha$ - or $\beta$-secretase generates two new peptides, $A \eta-\alpha$ and $A \eta-B$ (Willem et al., 2015). Importantly, APP processing is not restricted to the plasma membrane, but was also shown to occur within synaptic vesicles (Del Prete et al., 2014).

\section{APPS $\alpha$ PROMOTES SYNAPTIC PLASTICITY}

Numerous studies showed that the $\alpha$-secretase released ectodomain APPs $\alpha$ exerts a role in neuroprotection, synaptic plasticity, and within neuronal networks (Ring et al., 2007; Weyer et al., 2011; Kögel et al., 2012). The acute synaptic function of endogenous APPs $\alpha$ in the adult brain was shown by using APP/APLP2 cDKO mice (Hick et al., 2015). One hour incubation with $10 \mathrm{nM}$ recombinant APPs $\alpha$ peptide (recAPPs $\alpha$ ) rescued the severe LTP deficit in acute slices of the mutants indicating that the soluble ectodomain acts on a rapid time-scale. These results were in line with previous findings of Taylor et al. (2008) reporting that intrahippocampal infusion of recAPPs $\alpha$ in the dentate gyrus (DG) of anesthetized rats enhances LTP recorded at the PP-DG pathway in vivo. Moreover, a recent study showed that recAPPs $\alpha$ is able to rescue age-dependent LTP deficits in vitro (Moreno et al., 2015). In addition, we showed that virus driven long-term expression of APPs $\alpha$ restores impaired synaptic plasticity in a mouse model of AD (Fol et al., 2016). It is by now not clear how APPs $\alpha$ mediates the rescue and which receptor might be activated. Overall there is good evidence for a prominent role of APPs $\alpha$ at the postsynapse, in particular by influencing NMDA-R function and synaptodendritic protein synthesis (Taylor et al., 2008; Claasen et al., 2009).

\section{MODULATION OF POSTSYNAPTIC FUNCTION BY APPS $\alpha$}

One possible mechanism of APPs $\alpha$ action at synapses might be the facilitation of evoked NMDA-R currents at the postsynapse as shown in the study of Taylor et al. (2008). These results were confirmed by acute application of recAPPs $\alpha$ on acute slices of APP/APLP2 cDKO mice or aged rats restoring the LTP induction deficit and highlighting that APPs $\alpha$ modulates synaptic plasticity and regulates early events of the LTP processes (Hick et al., 2015; Moreno et al., 2015). Both studies further report that exogenous applied APPs $\alpha$ does not affect basal synaptic transmission or glutamate release. NMDA-Rs may stimulate $\alpha$ secretase cleavage of APP during high-frequency stimulation (HFS) or HFS activates metabotropic glutamate (mGluRs) or muscarinic acetylcholine receptors (mAChRs) to promote APPs $\alpha$ release. Notably, the processing must be tightly regulated as high APPs $\alpha$ concentrations reduce LTP induction by activation of inhibitory signaling pathways (Taylor et al., 2008). The concentration dependent action of APPs $\alpha$ to increase NMDA$\mathrm{R}$ currents could further be linked to D-serine availability at the synapse (Moreno et al., 2015). D-serine is the main coagonist required for NMDA-R activation (for details see review Billard, 2012) and APPs $\alpha$ stimulates it's production and release. A recent study further showed that APP deficiency is linked to alterations in D-serine levels accompanied by impaired structural plasticity of dendritic spines (Zou et al., 2016). Facilitation of LTP expression by APPs $\alpha$ might also be mediated through the induction of a subset of plasticity-associated immediate early genes (Ryan et al., 2013), with de novo protein synthesis 
taking place in synaptoneurosomes mainly by activation of protein kinase G (Claasen et al., 2009). Among APPs $\alpha$ activated signaling cascades are furthermore the phosphatidylinositol-3kinase (PI(3)K)-Akt kinase signaling pathway (Cheng et al., 2002; Milosch et al., 2014) and the mitogen-activated protein (MAP) kinase signaling pathway (Greenberg et al., 1995; Cheng et al., 2002).

Taken together, APPs $\alpha$ initiates several intracellular signaling cascades to support synaptic activity with an impact on NMDA$\mathrm{R}$ currents, but still the APPs $\alpha$-specific receptor triggering the effect on NMDA-Rs remains so far elusive. At least the experiments performed by Reinhard et al. (2013) could show that APPs $\alpha$ binding to a cell surface receptor involves two different subdomains. The N-terminal growth factor like domain (GFLD) of APPs $\alpha$ mediates the binding of protein and receptor, while the E2 domain interacts with membrane-anchored heparin sulfate proteoglycans (HSPG) and thus enhances the affinity to the APPs $\alpha$-receptor. Among the potential receptors for which an interaction with the APP ectodomain is suggested are the lowdensity lipoprotein receptor-related protein (LRP1, Hoffmann et al., 1999; Goto and Tanzi, 2002), the sortilin-related receptor SORLA (Andersen et al., 2006; Hartl et al., 2013), Nogo-66 (Park et al., 2006), and the p75 neurotrophin receptor (Hasebe et al., 2013).

\section{INHIBITION OF APPS $\alpha$ MEDIATED FUNCTIONS}

In-line with the results following exogenous application of APPs $\alpha$ on LTP in vitro and in vivo are the opposite effects observed after $\alpha$-secretase inhibition (which leads to a reduction in APPs $\alpha$ production). The conditional KO of the major $\alpha$-secretase ADAM-10 resulted in strongly impaired LTP and altered STP (Prox et al., 2013). Within this study no differences in basic synaptic transmission were found. Interestingly, hippocampal network activity recorded in vivo in the CA1 region of the hippocampus of ADAM-10 cDKO mice was severely impaired and $20 \%$ of the animals showed electrographic seizures (Prox et al., 2013). A modulatory role for APPs $\alpha$ on network activity in the hippocampus and cortex has further been observed with regard to aging by Sánchez-Alavez et al. (2007) which recorded electroencephalographic activity. In addition, the key role of APPs $\alpha$ and APLP2s $\alpha$ for LTP induction and maintenance was shown by experiments using the ADAM-10 inhibitor in OHCs (Weyer et al., 2011) or by in vivo LTP recordings in the dentate gyrus after infusion of the $\alpha$-secretase inhibitor TAPI-1 (Taylor et al., 2008). Due to the lack of ADAM-10 or its inhibition, APP processing by the $B$-secretase is favored resulting in higher amounts of $A ß$ peptides and APPsß which may further impair LTP, especially at nano- to micromolar levels see review Wang $\mathrm{H}$. et al. (2012).

\section{APPSB DOES NOT MODULATE SYNAPTIC FUNCTION}

Only a few studies addressed the physiological action of the $B$-secretase which leads to the release of the ectodomain APPsß (see Figure 1). APPsß is only 16 amino acids shorter than APPs $\alpha$, but it is not as neuroprotective as APPs $\alpha$. This was demonstrated by the Knock-In of the two soluble domains in the perinatal APP/APLP2 DKO mutant model. Only APPs $\alpha^{+/+} \mathrm{APLP}^{-/-}$, but not $\mathrm{APPs}^{+/+} \mathrm{APLP}^{-/-}$mice were viable (Li et al., 2010; Weyer et al., 2011). With regard to synaptic plasticity, APPsß cannot restore the LTP defect of APP/APLP2 cDKO mice (Hick et al., 2015) and does not facilitate LTP recorded in vivo within the DG of rats (Taylor et al., 2008). APPsß was further shown to have no influence on synaptic protein synthesis (Claasen et al., 2009). Consistent with the functional readout on synapses, Tyan et al. (2012) showed that only APPs $\alpha$ but not APPs $\beta$ partially rescued defects in dendritic spine number and morphology of primary hippocampal neurons from APP-KO mice.

\section{AB DOMINANTLY ACTS AT THE PRESYNAPSE}

At physiological, picomolar concentrations $A ß$ was shown to modulate presynaptic vesicle release (Puzzo et al., 2008; Abramov et al., 2009; Wang H. et al., 2012). It functions via binding to presynaptic APP homodimers (Fogel et al., 2014) or by activating $\alpha 7$-nAChRs (Tong et al., 2011). The study by Lawrence et al. (2014) highlighted that the $\mathrm{N}$-terminal domain of $A B$ contains this agonist-like activity of the $A ß$ peptide. It was further suggested that successive $\alpha$ - and $\beta$-secretase activity will release the short functional domain, named Aß1-15 (or Aß116, Portelius et al., 2011). With regard to synaptic plasticity, Aß1-15 significantly enhances PTP and LTP without altering baseline synaptic transmission at femtomolar concentrations, while higher amounts had no effect on hippocampal LTP (Lawrence et al., 2014). During LTD, Aß was shown to have a facilitating role through $\mathrm{mGluR}$ and NMDA-R due to the altered glutamate recycling at synapses (Li et al., 2009; Chen et al., 2013). The pathological effects of $A ß$, especially $A ß 42$, are discussed in detail elsewhere (Mucke and Selkoe, 2012; Wang H. et al., 2012; Ripoli et al., 2014; Salgado-Puga and Pena-Ortega, 2015) We only want to mention that under pathological conditions $A ß$ has the opposite effects on synaptic plasticity: it facilitates LTD, depresses LTP, causes dendritic spine loss and leads to hippocampal hyperactivity (Selkoe, 2002; Busche et al., 2008; Shankar et al., 2008; Mucke and Selkoe, 2012; Fol et al., 2016).

\section{AN- $\alpha$ AND AN-B, THE NEW PLAYERS IN THE FIELD}

The recently identified $\eta$-secretase releases a short extracellular APP- $\eta$ ectodomain (Willem et al., 2015). The CTF $\eta$ cleavage product remains anchored to the plasma membrane and subsequently is further processed by $\alpha$ - or $\beta$ - secretases to produce two small peptides, $A \eta-\alpha$ and $A \eta-\beta$ (see Figure 1; Willem et al., 2015). Willem and colleagues assessed the synaptic function of these peptides by measuring LTP in vitro. While both peptides had no influence on baseline synaptic transmission,

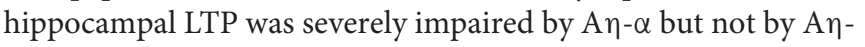
$ß$. The only structural difference between the two molecules is a C-terminal elongation of the A $\eta-\alpha$ peptide by 16 additional 
amino acids (Figure 1). Interestingly, the same 16 amino acids are also present at the C-terminus of the APPs $\alpha$ fragment and, similar to $A \eta-\beta$, are lacking in the truncated APPsß form (Figure 1). This short peptide sequence contains a predicted neuroprotective domain and a heparin binding site (Furukawa et al., 1996). Indeed, neuroprotective properties have been reported for the APPs $\alpha$ peptide. However, and in contradiction to a favorable cellular function of this amino acid sequence, it has been found that A $\eta-\alpha$ mediates neurotoxic effects (Willem et al., 2015). The adverse action of $\mathrm{A} \eta-\alpha$ was also observed by in vivo $\mathrm{Ca}^{2+}$ imaging experiments performed in the study of Willem et al. (2015) in which A $\eta-\alpha$ strongly suppressed the activity of hippocampal neurons. In line with these findings are the observations for both $ß$-derived peptides. It seems unlikely that these fragments are involved in synaptic plasticity since both $A \eta-\beta$ and APPsß lacked any modulatory effects on synaptic transmission when bath-applied to acute-hippocampal slices of APP/APLP2 cDKO mice at CA3-CA1 synapses (Hick et al., 2015) or when added during mossy fiber LTP recordings (Taylor et al., 2008). The different modes of action might be a consequence of a conformational change caused by the 16 additional amino acids at the carboxy-terminus of the A $\eta$ - $\alpha /$ APPs $\alpha$ cleavage products and/or by specific post-translational modifications (PTMs) like glycosylation or phosphorylation (Walter and Haass, 2000). In the study of Willem et al. (2015) A $-\alpha$ conditioned medium or $100 \mathrm{nM}$ synthetic A $\eta-\alpha$ showed a reduction in LTP, while only lower concentrations of 1-11 nM recombinant APPs $\alpha$ increased LTP. Moreover, the application of higher APPs $\alpha$ amounts had no effect or resulted even in reduced LTP (Taylor et al., 2008; Hick et al., 2015; Moreno et al., 2015). It would be interesting to know if APPs $\alpha$ can additionally be cleaved by $\eta$-secretase and if the released $A \eta-\alpha$ could act as a co-player for Aß or APPs $\alpha$ and would therefore provide a modulatory mechanism.

\section{KNOCK-IN OF APPS $\alpha$, APPSB, AND THE APP INTRACELLULAR DOMAIN (AICD)}

Beside the acute application of APP functional domains as peptides, gene targeting allows their re-introduction on APP or APLP2 null backgrounds. These conditional approaches or Knock-In (KI) mice opened the possibility of the functional characterization of the APP/APLP proteins during development as the constitutive triple $\mathrm{KO}$ and nearly all DKOs are embryonic lethal (von Koch et al., 1997; Heber et al., 2000). The study of Ring et al. (2007) analyzed the role of two APP functional domains by generating C-terminally truncated KI alleles of APP. APPs $\alpha$-KI mice produce only APPs $\alpha$, whereas APP $\triangle \mathrm{CT} 15-$ KI mice lack the last 15 amino acids, including the highly conserved YENPTY motif. The phenotypes of both KI lines were similar to WT littermates. LTP as well as learning and memory assessed in behavioral tasks were normal presumably due to the constitutive expression of APLP2. The subsequent combination of both KI mice with APLP2 null mutants generated partially viable offsprings, whereas APPs $\beta$-DM mice die ( $\mathrm{Li}$ et al., 2010). APPs $\alpha$-DMs were characterized in detail by Weyer et al. (2011) and APP $\triangle$ CT15-DMs in the study of Klevanski et al. (2015). Both DM strains display alterations at PNS and CNS synapses. The mice suffer of muscular weakness due to altered morphology of the NMJ synapse and impaired transmitter release. Still, the APPs $\alpha$-DMs reveal more severe electrophysiological impairments at the NMJ by additional reduced quantal content and alterations in the frequency of miniature endplate potentials (MEPP) compared to single mutants investigated by Ring et al. (2007). Hence different motifs account for a normal physiological function in the DMs. With regard to the CNS, both DMs are an impaired induction and maintenance of LTP paralleled by severely altered hippocampusdependent behavior. STP between CA3/CA1 pyramidal cells was unchanged, while only APP $\triangle \mathrm{CT} 15-\mathrm{DMs}$ have altered postsynaptic properties and a trend toward defective proteinsynthesis dependent Late-LTP.

\section{AICD Is Crucial at Both Sites of the Synapse}

The sole expression of AICD on an APP/APLP2 deficient background revealed alterations in synaptic plasticity. This might be a consequence of the abolished interaction of the intracellular domain with several adaptor proteins (Klevanski et al., 2015). For instance, APP interaction partners like Dab1, Shc, Grb, and Mint/X11 proteins mediate not only clathrin-mediated endocytosis of APP, but are also involved in the translocation of APP to the cell-surface (Aydin et al., 2012; van der Kant and Goldstein, 2015). Of particular importance might be the interaction with the adapter protein family FE65.I Interestingly FE65/FE65L1double deficient mice show a similar phenotype of cortical dysplasia as APP triple KO animals (Guénette et al., 2006). The FE65 proteins colocalize with APP in the ER and Golgi and facilitate the translocation of the precursor protein to the cell surface (Sabo et al., 1999). In addition, these proteins also regulate the shuttling of a multimeric complex of AICD/FE65/Tip60 into the nucleus to regulate gene transcription (Cao and Südhof, 2001). Long-lasting strengthening of synaptic transmission is impaired in APP $\triangle$ CT15-DMs perhaps by impaired FE65/AICD mediated postsynaptic transcriptional activity (Klevanski et al., 2015). Interestingly, the analysis of FE65-KO, FE65L1-KO, and FE65/FE65L1-DKO mice revealed similar CNS phenotypes with impairments in LTP and dysfunctions in hippocampal learning tasks in double transgenic animals (Strecker et al., 2016). Accordingly, the APP-FE65 interaction might be crucial for synaptic function, but also for precise ectodomain shedding. In APP $\triangle$ CT15-DMs mice, processing of APP via the amyloidogenic pathway is heavily impaired (Klevanski et al., 2015). That might have a positive effect with regard to $A ß$ accumulation but also a negative outcome since picomolar amounts of $A B$ positively regulate the presynaptic vesicle release probability and facilitate learning and LTP in the hippocampal CA1 region by activating $\alpha 7-n A C h R s$ (reviewed by Wang H. et al., 2012). Collectively, these studies highlight an essential function for the 15 C-terminal amino acids including the YENPTY motif for transmembrane signaling and the ectodomain APPs $\alpha$ for proper synapse function. 


\section{CONCLUSION}

The majority of experimental data provided so far indicate a requirement for APP and APLP2 in synaptic plasticity which is in particular mediated by their proteolytic derived domains. The diverse functions of the APP protein family during either preor postsynaptically initiated processes of synaptic plasticity and under basal conditions are summarized in Figure 2. According to this model, APP full length proteins mediate stability of synaptic structures by their cell adhesion properties when integrated into the plasma membrane (Kaden et al., 2009; Baumkötter et al., 2012) and thus maintain appropriate spine numbers, especially via the APPs $\alpha$ domain (Tyan et al., 2012; Weyer et al., 2014). The insertion of full-length proteins is regulated by electrical activity or gradients of ions like zinc. The APLP1 protein shows the highest presence at the cell surface among all APP protein family members (Kaden et al., 2009; Mayer et al., 2016). As indicated Figure 2B depicts the APP protein family function at the presynaptic site, where the $A ß, A ß-15$ and possibly the $A P P s \alpha$ domain interfere with glutamate release by activating nAChRs and enhancing intracellular $\mathrm{Ca}^{2+}$ levels (Puzzo et al., 2008; Wang Z. et al., 2012; Lawrence et al., 2014). It is further hypothesized that homodimerized APP acts as a G-Protein coupled receptor which is activated by $A ß$ and might be involved in neurotransmitter release following enhanced $\mathrm{Ca}^{2+}$ influx. Especially the intracellular domains of APP and APLP2 seem to be associated with proteins of the synaptic vesicle release machinery regulating the molecular composition of synaptic vesicles at the presynaptic active zone (Del Prete et al., 2014; Fanutza et al., 2015; Laßek et al., 2015). At the postsynaptic compartment (Figure 2C) patterns of synaptic activity modulate APP family protein processing. HFS enhances the amount of secreted APPs $\alpha$ possibly linked to mGluRs or AChRs activation (Nitsch et al., 1992, 1997). Released APPs $\alpha$ was shown to facilitate NMDA-R currents (Taylor et al., 2008; Weyer et al., 2011) by increasing the NMDA-R agonist D-serine (Moreno

\section{REFERENCES}

Abramov, E., Dolev, I., Fogel, H., Ciccotosto, G. D., Ruff, E., and Slutsky, I. (2009). Amyloid- $\beta$ as a positive endogenous regulator of release probability at hippocampal synapses. Nat. Neurosci. 12, 1567-1576. doi: 10.1038/ nn. 2433

Andersen, O. M., Schmidt, V., Spoelgen, R., Gliemann, J., Behlke, J., Galatis, D., et al. (2006). Molecular dissection of the interaction between amyloid precursor protein and its neuronal trafficking receptor SorLA/LR11. Biochemistry 45, 2618-2628. doi: 10.1021/bi052120v

Aydin, D., Weyer, S. W., and Müller, U. C. (2012). Functions of the APP gene family in the nervous system: insights from mouse models. Exp. Brain Res. 217, 423-434. doi: 10.1007/s00221-011-2861-2

Bakker, A., Krauss, G. L., Albert, M. S., Speck, C. L., Jones, L. R., Stark, C. E., et al. (2012). Reduction of hippocampal hyperactivity improves cognition in amnestic mild cognitive impairment. Neuron 74, 467-474. doi: 10.1016/j.neuron.2012.03.023

Baumkötter, F., Schmidt, N., Vargas, C., Schilling, S., Weber, R., Wagner, K., et al. (2014). Amyloid precursor protein dimerization and synaptogenic function depend on copper binding to the growth factorlike domain. J. Neurosci. 34, 11159-11172. doi: 10.1523/JNEUROSCI.018014.2014 et al., 2015) or by up-regulating signaling cascades downstream of NMDA-Rs- promoting synaptic plasticity like the CamKII pathway (Claasen et al., 2009) or by inducing the expression of immediate early genes involved in synaptic plasticity (Ryan et al., 2013). In this regard only APPs $\alpha$ was shown to have trophic functions while APPsß mediates neither positive nor negative effects with respect to baseline synaptic function or synaptic plasticity (Taylor et al., 2008; Hick et al., 2015). Several lines of evidence indicate that under physiological conditions structural and functional synaptic modulation is mediated by APPs $\alpha$. What still needs to be investigated, however, is the mechanism by which APPs $\alpha$ exerts its trophic action, particularly which receptor might be activated and if the recently discovered A $\eta$ peptides might function as regulators of APPs $\alpha$ mediated synaptic plasticity and homeostasis. Identifying the cellular site of $\eta$-secretase cleavage within neurons and answering whether the secretion of An peptides is linked to neuronal activity will reveal the roles of the peptides in processes of synaptic plasticity.

Overall elucidating the physiological function of APP family members and fragments is an important step to understand brain function as well as brain dysfunction, also with respect to a possible treatment of neurodegenerative disorders like $\mathrm{AD}$. It is important to acknowledge, that rational therapeutic approaches need to take into account the functional role of disease associated proteins.

\section{AUTHOR CONTRIBUTIONS}

SL: wrote the review and prepared the figures. MK: designed the review and wrote the paper.

\section{FUNDING}

This work was supported by the Deutsche Forschungsgemeinschaft Grants (KO 1674/3-1, 3-2) to MK.
Baumkötter, F., Wagner, K., Eggert, S., Wild, K., and Kins, S. (2012). Structural aspects and physiological consequences of APP/APLP trans-dimerization. Exp. Brain Res. 217, 389-395. doi: 10.1007/s00221-011-2878-6

Bendotti, C., Forloni, G. L., Morgan, R. A., O’Hara, B. F., Oster-Granite, M. L., Reeves, R. H., et al. (1988). Neuroanatomical localization and quantification of amyloid precursor protein mRNA by in situ hybridization in the brains of normal, aneuploid, and lesioned mice. Proc. Natl. Acad. Sci. U.S.A. 85, 3628-3632. doi: 10.1073/pnas.85.10.3628

Billard, J. M. (2012). D-Amino acids in brain neurotransmission and synaptic plasticity. Amino Acids 43, 1851-1860. doi: 10.1007/s00726-012-1346-3

Bliss, T. V., and Collingridge, G. L. (1993). A synaptic model of memory: long-term potentiation in the hippocampus. Nature 361, 31-39. doi: 10.1038/361031a0

Bliss, T. V., and Lomo, T. (1973). Long-lasting potentiation of synaptic transmission in the dentate area of the anaesthetized rabbit following stimulation of the perforant path. J. Physiol. 232, 331-356. doi: 10.1113/jphysiol.1973.sp010273

Born, H. A., Kim, J. Y., Savjani, R. R., Das, P., Dabaghian, Y. A., Guo, Q., et al. (2014). Genetic suppression of transgenic APP rescues Hypersynchronous network activity in a mouse model of Alzeimer's disease. J. Neurosci. 34, 3826-3840. doi: 10.1523/JNEUROSCI.5171-13.2014

Busche, M. A., Eichhoff, G., Adelsberger, H., Abramowski, D., Wiederhold, K. H., Haass, C., et al. (2008). Clusters of hyperactive neurons near amyloid 
plaques in a mouse model of Alzheimer's disease. Science 321, 1686-1689. doi: $10.1126 /$ science. 1162844

Caldwell, J. H., Klevanski, M., Saar, M., and Müller, U. C. (2013). Roles of the amyloid precursor protein family in the peripheral nervous system. Mech. Dev. 130, 433-446. doi: 10.1016/j.mod.2012.11.001

Cao, X., and Südhof, T. C. (2001). A transcriptionally [correction of transcriptively] active complex of APP with Fe65 and histone acetyltransferase Tip60. Science 293, 115-120. doi: 10.1126/science.1058783

Casasola, C., Montiel, T., Calixto, E., and Brailowsky, S. (2004). Hyperexcitability induced by GABA withdrawal facilitates hippocampal long-term potentiation. Neuroscience 126, 163-171. doi: 10.1016/j.neuroscience.2004.03.029

Chen, X., Lin, R., Chang, L., Xu, S., Wei, X., Zhang, J., et al. (2013). Enhancement of long-term depression by soluble amyloid $\alpha$ protein in rat hippocampus is mediated by metabotropic glutamate receptor and involves activation of p38MAPK, STEP, and caspase-3. Neuroscience 253, 435-443. doi: 10.1016/j.neuroscience.2013.08.054

Cheng, G., Yu, Z., Zhou, D., and Mattson, M. P. (2002). Phosphatidylinositol3-kinase-Akt kinase and p42/p44 mitogen-activated protein kinases mediate neurotrophic and excitoprotective actions of a secreted form of amyloid precursor protein. Exp. Neurol. 175, 407-414. doi: 10.1006/exnr.2002.7920

Claasen, A. M., Guévremont, D., Mason-Parker, S. E., Bourne, K., Tate, W. P., Abraham, W. C., et al. (2009). Secreted amyloid precursor protein$\alpha$ upregulates synaptic protein synthesis by a protein kinase G-dependent mechanism. Neurosci. Lett. 460, 92-96. doi: 10.1016/j.neulet.2009.05.040

Cousins, S. L., Dai, W., and Stephenson, F. A. (2015). APLP1 and APLP2, members of the APP family of proteins, behave similarly to APP in that they associate with NMDA receptors and enhance NMDA receptor surface expression. J. Neurochem. 133, 879-885. doi: 10.1111/jnc.13063

Del Prete, D., Lombino, F., Liu, X., and D'Adamio, L. (2014). APP is cleaved by Bacel in pre-synaptic vesicles and establishes a pre-synaptic interactome, via its intracellular domain, with molecular complexes that regulate pre-synaptic vesicles functions. PLoS ONE 9:e108576. doi: 10.1371/journal.pone.0108576

Dyrks, T., Weidemann, A., Multhaup, G., Salbaum, J. M., Lemaire, H. G., Kang, J., et al. (1988). Identification, transmembrane orientation and biogenesis of the amyloid A4 precursor of Alzheimer's disease. EMBO J. 7, 949-957.

Eggert, S., Paliga, K., Soba, P., Evin, G., Masters, C. L., Weidemann, A., et al. (2004). The proteolytic processing of the amyloid precursor protein gene family members APLP-1 and APLP-2 involves $\alpha$-, $\beta$-, $\gamma$-, and $\epsilon$-like cleavages: modulation of APLP-1 processing by n-glycosylation. J. Biol. Chem. 279, 18146-18156. doi: 10.1074/jbc.M311601200

Fanutza, T., Del Prete, D., Ford, M. J., Castillo, P. E., and D'Adamio, L. (2015). APP and APLP2 interact with the synaptic release machinery and facilitate transmitter release at hippocampal synapses. Elife 4:e09743. doi: 10.7554/eLife.09743

Fazeli, M. S., Breen, K., Errington, M. L., and Bliss, T. V. (1994). Increase in extracellular NCAM and amyloid precursor protein following induction of long-term potentiation in the dentate gyrus of anaesthetized rats. Neurosci. Lett. 169, 77-80. doi: 10.1016/0304-3940(94)90360-3

Fitzjohn, S. M., Morton, R. A., Kuenzi, F., Davies, C. H., Seabrook, G. R., and Collingridge, G. L. (2000). Similar levels of long-term potentiation in amyloid precursor protein -null and wild-type mice in the CA1 region of picrotoxin treated slices. Neurosci. Lett. 288, 9-12. doi: 10.1016/S0304-3940(00) 01204-0

Fogel, H., Frere, S., Segev, O., Bharill, S., Shapira, I., Gazit, N., et al. (2014). APP homodimers transduce an amyloid- $\alpha$-mediated increase in release probability at excitatory synapses. Cell Rep. 7, 1560-1576. doi: 10.1016/j.celrep.2014.04.024

Fol, R., Braudeau, J., Ludewig, S., Abel, T., Weyer, S. W., Roederer, J.P., et al. (2016). Viral gene transfer of APPs $\alpha$ rescues synaptic failure in an Alzheimer's disease mouse model. Acta Neuropathol. 131, 247-266. doi: 10.1007/s00401-015-1498-9

Furukawa, K., Sopher, B. L., Rydel, R. E., Begley, J. G., Pham, D. G., Martin, G. M., et al. (1996). Increased activity-regulating and neuroprotective efficacy of $\alpha$-secretase-derived secreted amyloid precursor protein conferred by a C-terminal heparin-binding domain. J. Neurochem. 67, 1882-1896. doi: 10.1046/j.1471-4159.1996.67051882.x

Gakhar-Koppole, N., Hundeshagen, P., Mandl, C., Weyer, S. W., Allinquant, B., Müller, U., et al. (2008). Activity requires soluble amyloid precursor protein $\alpha$ to promote neurite outgrowth in neural stem cell-derived neurons via activation of the MAPK pathway. Eur. J. Neurosci. 28, 871-882. doi: 10.1111/j.1460-9568.2008.06398.x

Goto, J. J., and Tanzi, R. E. (2002). The role of the low-density lipoprotein receptor-related protein (LRP1) in Alzheimer's A $\beta$ generation: development of a cell-based model system. J. Mol. Neurosci. 19, 37-41. doi: 10.1007/s12031002-0008-4

Greenberg, S. M., Qiu, W. Q., Selkoe, D. J., Ben-Itzhak, A., and Kosik, K. S. (1995). Amino-terminal region of the $\beta$-amyloid precursor protein activates mitogen-activated protein kinase. Neurosci. Lett. 198, 52-56. doi: 10.1016/0304-3940(95)11944-R

Guénette, S., Chang, Y., Hiesberger, T., Richardson, J. A., Eckman, C. B., Eckman, E. A., et al. (2006). Essential roles for the FE65 amyloid precursor protein-interacting proteins in brain development. EMBO J. 25, 420-431. doi: 10.1038/sj.emboj.7600926

Guo, Q., Wang, Z., Li, H., Wiese, M., and Zheng, H. (2012). APP physiological and pathophysiological functions: insights from animal models. Cell Res. 22, 78-89. doi: $10.1038 / \mathrm{cr} .2011 .116$

Gustafsson, B., and Wigström, H. (1988). Physiological mechanisms underlying long-term potentiation. Trends Neurosci. 11, 156-162. doi: 10.1016/0166-2236(88)90142-7

Hartl, D., Klatt, S., Roch, M., Konthur, Z., Klose, J., Willnow, T. E., et al. (2013). Soluble $\alpha$-APP (sAPP $\alpha)$ Regulates CDK5 expression and activity in neurons. PLoS ONE 8:e65920. doi: 10.1371/journal.pone.0065920

Hasebe, N., Fujita, Y., Ueno, M., Yoshimura, K., Fujino, Y., and Yamashita, T. (2013). Soluble $\alpha$-amyloid precursor protein $\alpha$ binds to p75 neurotrophin receptor to promote neurite outgrowth. PLOS ONE 8:e82321. doi: 10.1371/journal.pone.0082321

Heber, S., Herms, J., Gajic, V., Hainfellner, J., Aguzzi, A., Rülicke, T., et al. (2000). Mice with combined gene knock-outs reveal essential and partially redundant functions of amyloid precursor protein family members. J. Neurosci. 20, 7951-7963.

Hefter, D., Kaiser, M., Weyer, S. W., Papageorgiou, I. E., Both, M., Kann, O., et al. (2016). Amyloid precursor protein protects neuronal network function after hypoxia via control of voltage-gated calcium channels. J. Neurosci. 36, 8356-8371. doi: 10.1523/JNEUROSCI.4130-15.2016

Hick, M., Herrmann, U., Weyer, S. W., Mallm, J. P., Tschape, J. A., Borgers, M., et al. (2015). Acute function of secreted amyloid precursor protein fragment APPs $\alpha$ in synaptic plasticity. Acta Neuropathol. 129, 21-37. doi: 10.1007/s00401-014-1368-x

Hoffmann, J., Pietrzik, C. U., Kummer, M. P., Twiesselmann, C., Bauer, C., and Herzog, V. (1999). Binding and selective detection of the secretory $\mathrm{N}$-terminal domain of the Alzheimer amyloid precursor protein on cell surfaces. J. Histochem. Cytochem. 47, 373-382. doi: 10.1177/0022155499047 00311

Isbert, S., Wagner, K., Eggert, S., Schweitzer, A., Multhaup, G., Weggen, S., et al. (2012). APP dimer formation is initiated in the endoplasmic reticulum and differs between APP isoforms. Cell. Mol. Life Sci. 69, 1353-1375. doi: 10.1007/s00018-011-0882-4

Jacobsen, K. T., and Iverfeldt, K. (2009). Amyloid precursor protein and its homologues: a family of proteolysis-dependent receptors. Cell. Mol. Life Sci. 66, 2299-2318. doi: 10.1007/s00018-009-0020-8

Kaden, D., Voigt, P., Munter, L. M., Bobowski, K. D., Schaefer, M., and Multhaup, G. (2009). Subcellular localization and dimerization of APLP1 are strikingly different from APP and APLP2. J. Cell Sci. 122, 368-377. doi: $10.1242 /$ jcs. 034058

Kamenetz, F., Tomita, T., Hsieh, H., Seabrook, G., Borchelt, D., Iwatsubo, T., et al. (2003). APP processing and synaptic function. Neuron 37, 925-937. doi: 10.1016/S0896-6273(03)00124-7

Kandel, E. R. (2001). The molecular biology of memory storage: a dialogue between genes and synapses. Science 294, 1030-1038. doi: 10.1126/science.1067020

Kim, T. W., Wu, K., Xu, J. L., McAuliffe, G., Tanzi, R. E., Wasco, W., et al. (1995). Selective localization of amyloid precursor-like protein 1 in the cerebral cortex postsynaptic density. Brain Res. Mol. Brain Res. 32, 36-44. doi: 10.1016/0169-328X(95)00328-P

Klevanski, M., Herrmann, U., Weyer, S. W., Fol, R., Cartier, N., Wolfer, D. P., et al. (2015). The APP intracellular domain is required for normal synaptic morphology, synaptic plasticity, and hippocampus-dependent behavior. J. Neurosci. 35, 16018-16033. doi: 10.1523/jneurosci.2009-15.2015 
Klevanski, M., Saar, M., Baumkötter, F., Weyer, S. W., Kins, S., and Müller, U. C. (2014). Differential role of APP and APLPs for neuromuscular synaptic morphology and function. Mol. Cell. Neurosci. 61, 201-210. doi: 10.1016/j.mcn.2014.06.004

Kögel, D., Deller, T., and Behl, C. (2012). Roles of amyloid precursor protein family members in neuroprotection, stress signaling and aging. Exp. Brain Res. 217, 471-479. doi: 10.1007/s00221-011-2932-4

Korte, M., Herrmann, U., Zhang, X., and Draguhn, A. (2012). The role of APP and APLP for synaptic transmission, plasticity, and network function: lessons from genetic mouse models. Exp. Brain Res. 217, 435-440. doi: 10.1007/s00221-011-2894-6

Korte, M., and Schmitz, D. (2016). Cellular and system biology of memory: timing, molecules, and beyond. Physiol. Rev. 96, 647-693. doi: 10.1152/physrev.00010.2015

Laßek, M., Weingarten, J., Acker-Palmer, A., Bajjalieh, S. M., Muller, U., and Volknandt, W. (2014). Amyloid precursor protein knockout diminishes synaptic vesicle proteins at the presynaptic active zone in mouse brain. Curr. Alzheimer Res. 11, 971-980. doi: 10.2174/1567205011666141107152458

Laßek, M., Weingarten, J., Einsfelder, U., Brendel, P., Müller, U., and Volknandt, W. (2013). Amyloid precursor proteins are constituents of the presynaptic active zone. J. Neurochem. 127, 48-56. doi: 10.1111/jnc.12358

Laßek, M., Weingarten, J., Wegner, M., Mueller, B. F., Rohmer, M., Baeumlisberger, D., et al. (2016). APP Is a context-sensitive regulator of the hippocampal presynaptic active zone. PLoS Comput. Biol. 12:e1004832. doi: 10.1371/journal.pcbi.1004832

Laßek, M., Weingarten, J., Wegner, M., and Volknandt, W. (2015). The Amyloid precursor protein-a novel player within the molecular array of presynaptic nanomachines. Front. Synaptic Neurosci. 7:21. doi: 10.3389/fnsyn.2015.00021

Lawrence, J. L., Tong, M., Alfulaij, N., Sherrin, T., Contarino, M., White, M. M., et al. (2014). Regulation of presynaptic $\mathrm{Ca}^{2+}$, synaptic plasticity and contextual fear conditioning by a N-terminal $\alpha$-amyloid fragment. J. Neurosci. 34, 14210-14218. doi: 10.1523/JNEUROSCI.0326-14.2014

LeBlanc, A. C., Papadopoulos, M., Bélair, C., Chu, W., Crosato, M., Powell, J., et al. (1997). Processing of amyloid precursor protein in human primary neuron and astrocyte cultures. J. Neurochem. 68, 1183-1190. doi: 10.1046/j.1471-4159.1997.68031183.x

Lee, K. J., Moussa, C. E., Lee, Y., Sung, Y., Howell, B. W., Turner, R. S., et al. (2010). Beta amyloid-independent role of amyloid precursor protein in generation and maintenance of dendritic spines. Neuroscience 169, 344-356. doi: 10.1016/j.neuroscience.2010.04.078

Leissring, M. A., Murphy, M. P., Mead, T. R., Akbari, Y., Sugarman, M. C., Jannatipour, M., et al. (2002). A physiologic signaling role for the $\gamma$-secretasederived intracellular fragment of APP. Proc. Natl. Acad. Sci. U.S.A. 99, 4697-4702. doi: 10.1073/pnas.072033799

Li, H., Wang, B., Wang, Z., Guo, Q., Tabuchi, K., Hammer, R. E., et al. (2010). Soluble amyloid precursor protein (APP) regulates transthyretin and Klotho gene expression without rescuing the essential function of APP. Proc. Natl. Acad. Sci. U.S.A. 107, 17362-17367. doi: 10.1073/pnas.1012568107

Li, S., Hong, S., Shepardson, N. E., Walsh, D. M., Shankar, G. M., and Selkoe, D. (2009). Soluble oligomers of amyloid $\beta$ protein facilitate hippocampal longterm depression by disrupting neuronal glutamate uptake. Neuron $62,788-801$. doi: 10.1016/j.neuron.2009.05.012

Liu, X., Yu, X., Zack, D. J., Zhu, H., and Qian, J. (2008). TiGER: a database for tissue-specific gene expression and regulation. BMC Bioinformatics 9:271. doi: 10.1186/1471-2105-9-271

Lorent, K., Overbergh, L., Moechars, D., De, S. B., Van, L. F., and Van den Berghe, H. (1995). Expression in mouse embryos and in adult mouse brain of three members of the amyloid precursor protein family, of the $\alpha-2$ macroglobulin receptor/low density lipoprotein receptor-related protein and of its ligands apolipoprotein E, lipoprotein lipase, $\alpha$-2-macroglobulin and the 40,000 molecular weight receptor-associated protein. Neuroscience 65, 1009-1025. doi: 10.1016/0306-4522(94)00555-J

Mayer, M. C., Schauenburg, L., Thompson-Steckel, G., Dunsing, V., Kaden, D., Voigt, P., et al. (2016). Amyloid precursor-like protein 1 (APLP1) exhibits stronger zinc-dependent neuronal adhesion than amyloid precursor protein and APLP2. J. Neurochem. 137, 266-276. doi: 10.1111/jnc.13540

Midthune, B., Tyan, S.-H., Walsh, J. J., Sarsoza, F., Eggert, S., Hof, P. R., et al. (2012). Deletion of the amyloid precursor-like protein 2 (APLP2) does not affect hippocampal neuron morphology or function. Mol. Cell. Neurosci. 49, 448-455. doi: 10.1016/j.mcn.2012.02.001

Milosch, N., Tanriover, G., Kundu, A., Rami, A., Francois, J. C., Baumkotter, F., et al. (2014). Holo-APP and G-protein-mediated signaling are required for sAPP $\alpha$-induced activation of the Akt survival pathway. Cell Death Dis. 5:e1391. doi: $10.1038 /$ cddis. 2014.352

Minkeviciene, R., Rheims, S., Dobszay, M. B., Zilberter, M., Hartikainen, J., Fülöp, L., et al. (2009). Amyloid $\beta$-induced neuronal hyperexcitability triggers progressive epilepsy. J. Neurosci. 29, 3453-3462. doi: 10.1523/JNEUROSCI.5215-08.2009

Moreno, L., Rose, C., Mohanraj, A., Allinquant, B., Billard, J.-M., and Dutar, P. (2015). sA $\beta P P \alpha$ improves hippocampal NMDA-dependent functional alterations linked to healthy aging. J. Alzheimers Dis. 48, 927-935. doi: 10.3233/JAD-150297

Mucke, L., and Selkoe, D. J. (2012). Neurotoxicity of amyloid $\beta$-protein: synaptic and network dysfunction. Cold Spring Harb. Perspect. Med. 2:a006338. doi: $10.1101 /$ cshperspect.a006338

Müller, U. C., and Zheng, H. (2012). Physiological functions of APP family proteins. Cold Spring Harb. Perspect. Med. 2:a006288. doi: $10.1101 /$ cshperspect.a006288

Nitsch, R. M., Deng, A., Wurtman, R. J., and Growdon, J. H. (1997) Metabotropic glutamate receptor subtype $\mathrm{mGluR} 1 \alpha$ stimulates the secretion of the amyloid $\beta$-protein precursor ectodomain. J. Neurochem. 69, 704-712. doi: 10.1046/j.1471-4159.1997.69020704.x

Nitsch, R. M., Farber, S. A., Growdon, J. H., and Wurtman, R. J. (1993) Release of amyloid $\beta$-protein precursor derivatives by electrical depolarization of rat hippocampal slices. Proc. Natl. Acad. Sci. U.S.A. 90, 5191-5193. doi: 10.1073/pnas.90.11.5191

Nitsch, R. M., Slack, B. E., Wurtman, R. J., and Growdon, J. H. (1992). Release of Alzheimer amyloid precursor derivatives stimulated by activation of muscarinic acetylcholine receptors. Science 258, 304-307. doi: $10.1126 /$ science. 1411529

Norstrom, E. M., Zhang, C., Tanzi, R., and Sisodia, S. S. (2010). Identification of NEEP21 as a ss-amyloid precursor protein-interacting protein in vivo that modulates amyloidogenic processing in vitro. J. Neurosci. 30, 15677-15685. doi: 10.1523/JNEUROSCI.4464-10.2010

Palop, J. J., Chin, J., Roberson, E. D., Wang, J., Thwin, M. T., Bien-Ly, N., et al. (2007). Aberrant excitatory neuronal activity and compensatory remodeling of inhibitory hippocampal circuits in mouse models of Alzheimer's disease. Neuron 55, 697-711. doi: 10.1016/j.neuron.2007.07.025

Park, J. H., Gimbel, D. A., GrandPre, T., Lee, J.-K., Kim, J.-E., Li, W., et al. (2006). Alzheimer precursor protein interaction with the Nogo-66 receptor reduces amyloid- $\beta$ plaque deposition. J. Neurosci. 26, 1386-1395. doi: 10.1523/JNEUROSCI.3291-05.2006

Perez, R. G., Soriano, S., Hayes, J. D., Ostaszewski, B., Xia, W., Selkoe, D. J., et al. (1999). Mutagenesis identifies new signals for $\beta$-amyloid precursor protein endocytosis, turnover, and the generation of secreted fragments, including A $\beta 42$. J. Biol. Chem. 274, 18851-18856. doi: 10.1074/jbc.274.27. 18851

Portelius, E., Price, E., Brinkmalm, G., Stiteler, M., Olsson, M., Persson, R., et al. (2011). A novel pathway for amyloid precursor protein processing. Neurobiol. Aging 32, 1090-1098. doi: 10.1016/j.neurobiolaging.2009.06.002

Prox, J., Bernreuther, C., Altmeppen, H., Grendel, J., Glatzel, M., D’Hooge, R., et al. (2013). Postnatal disruption of the disintegrin/metalloproteinase ADAM10 in brain causes epileptic seizures, learning deficits, altered spine morphology, and defective synaptic functions. J. Neurosci. 33, 12915-28, 12928a. doi: 10.1523/jneurosci.5910-12.2013

Puzzo, D., Privitera, L., Leznik, E., Fa, M., Staniszewski, A., Palmeri, A., et al. (2008). Picomolar amyloid- $\alpha$ positively modulates synaptic plasticity and memory in hippocampus. J. Neurosci. 28, 14537-14545. doi: 10.1523/JNEUROSCI.2692-08.2008

Reinhard, C., Borgers, M., David, G., and De Strooper, B. (2013). Soluble amyloid- $\beta$ precursor protein binds its cell surface receptor in a cooperative fashion with glypican and syndecan proteoglycans. J. Cell Sci. 126, 4856-4861. doi: $10.1242 /$ jcs. 137919

Ring, S., Weyer, S. W., Kilian, S. B., Waldron, E., Pietrzik, C. U., Filippov, M. A., et al. (2007). The secreted $\alpha$-amyloid precursor protein ectodomain APPs $\alpha$ is sufficient to rescue the anatomical, behavioral, and electrophysiological 
abnormalities of APP-deficient mice. J. Neurosci. 27, 7817-7826. doi: 10.1523/JNEUROSCI.1026-07.2007

Ripoli, C., Cocco, S., Li Puma, D. D., Piacentini, R., Mastrodonato, A., Scala, F., et al. (2014). Intracellular accumulation of amyloid- $\alpha(\mathrm{A} \alpha)$ protein plays a major role in $\mathrm{A} \alpha$-induced alterations of glutamatergic synaptic transmission and plasticity. J. Neurosci. 34, 12893-12903. doi: 10.1523/JNEUROSCI.1201-14.2014

Robakis, N. K., Ramakrishna, N., Wolfe, G., and Wisniewski, H. M. (1987). Molecular cloning and characterization of a cDNA encoding the cerebrovascular and the neuritic plaque amyloid peptides. Proc. Natl. Acad. Sci. U.S.A. 84, 4190-4194. doi: 10.1073/pnas.84.12.4190

Rohan de Silva, H. A., Jen, A., Wickenden, C., Jen, L. S., Wilkinson, S. L., and Patel, A. J. (1997). Cell-specific expression of $\beta$-amyloid precursor protein isoform mRNAs and proteins in neurons and astrocytes. Brain Res. Mol. Brain Res. 47, 147-156. doi: 10.1016/S0169-328X(97)00045-4

Ryan, M. M., Morris, G. P., Mockett, B. G., Bourne, K., Abraham, W. C., Tate, W. P., et al. (2013). Time-dependent changes in gene expression induced by secreted amyloid precursor protein- $\alpha$ in the rat hippocampus. BMC Genomics 14:376. doi: 10.1186/1471-2164-14-376

Sabo, S. L., Lanier, L. M., Ikin, A. F., Khorkova, O., Sahasrabudhe, S., Greengard, P., et al. (1999). Regulation of $\beta$-amyloid secretion by FE65, an amyloid protein precursor-binding protein. J. Biol. Chem. 274, 7952-7957. doi: $10.1074 / \mathrm{jbc} .274 .12 .7952$

Salgado-Puga, K., and Pena-Ortega, F. (2015). Cellular and network mechanisms underlying memory impairment induced by amyloid $\beta$ protein. Protein Pept. Lett. 22, 303-321. doi: 10.2174/0929866522666150202112154

Sánchez-Alavez, M., Chan, S. L., Mattson, M. P., and Criado, J. R. (2007). Electrophysiological and cerebrovascular effects of the $\alpha$-secretase-derived form of amyloid precursor protein in young and middle-aged rats. Brain Res. 1131, 112-117. doi: 10.1016/j.brainres.2006.10.074

Schwenk, J., Pérez-Garci, E., Schneider, A., Kollewe, A., Gauthier-Kemper, A., Fritzius, T., et al. (2016). Modular composition and dynamics of native $G_{A B A}$ receptors identified by high-resolution proteomics. Nat. Neurosci. 19, 233-242. doi: $10.1038 / \mathrm{nn} .4198$

Seabrook, G. R., Smith, D. W., Bowery, B. J., Easter, A., Reynolds, T., Fitzjohn, S. M., et al. (1999). Mechanisms contributing to the deficits in hippocampal synaptic plasticity in mice lacking amyloid precursor protein. Neuropharmacology 38, 349-359. doi: 10.1016/S0028-3908(98)00204-4

Selkoe, D. J. (2002). Alzheimer's disease is a synaptic failure. Science 298, 789-791. doi: $10.1126 /$ science. 1074069

Shankar, G. M., Li, S., Mehta, T. H., Garcia-Munoz, A., Shepardson, N. E., Smith, I., et al. (2008). Amyloid- $\beta$ protein dimers isolated directly from Alzheimer's brains impair synaptic plasticity and memory. Nat. Med. 14, 837-842. doi: $10.1038 / \mathrm{nm} 1782$

Slunt, H. H., Thinakaran, G., Von Koch, C., Lo, A. C., Tanzi, R. E., and Sisodia, S. $S$. (1994). Expression of a ubiquitous, cross-reactive homologue of the mouse $\beta$-amyloid precursor protein (APP). J. Biol. Chem. 269, 2637-2644.

Soba, P., Eggert, S., Wagner, K., Zentgraf, H., Siehl, K., Kreger, S., et al. (2005). Homo- and heterodimerization of APP family members promotes intercellular adhesion. EMBO J. 24, 3624-3634. doi: 10.1038/sj.emboj.7600824

Stahl, R., Schilling, S., Soba, P., Rupp, C., Hartmann, T., Wagner, K., et al. (2014). Shedding of APP limits its synaptogenic activity and cell adhesion properties. Front. Cell. Neurosci. 8:410. doi: 10.3389/fncel.2014.00410

Steinbach, J. P., Müller, U., Leist, M., Li, Z. W., Nicotera, P., and Aguzzi, A. (1998). Hypersensitivity to seizures in $\beta$-amyloid precursor protein deficient mice. Cell Death Differ. 5, 858-866. doi: 10.1038/sj.cdd.4400391

Strecker, P., Ludewig, S., Rust, M., Mundinger, T. A., Görlich, A., Krächan, E. G., et al. (2016). FE65 and FE65L1 share common synaptic functions and genetically interact with the APP family in neuromuscular junction formation. Sci. Rep. 6:25652. doi: 10.1038/srep25652

Stuchlik, A. (2014). Dynamic learning and memory, synaptic plasticity and neurogenesis: an update. Front. Behav. Neurosci. 8:106. doi: 10.3389/fnbeh.2014.00106

Tan, J., and Evin, G. (2012). Beta-site APP-cleaving enzyme 1 trafficking and Alzheimer's disease pathogenesis. J. Neurochem. 120, 869-880. doi: 10.1111/j.1471-4159.2011.07623.x

Taylor, C. J., Ireland, D. R., Ballagh, I., Bourne, K., Marechal, N. M., Turner, P. R., et al. (2008). Endogenous secreted amyloid precursor protein- $\alpha$ regulates hippocampal NMDA receptor function, long-term potentiation and spatial memory. Neurobiol. Dis. 31, 250-260. doi: 10.1016/j.nbd.2008.04.011

Thinakaran, G., and Koo, E. H. (2008). Amyloid precursor protein trafficking, processing, and function. J. Biol. Chem. 283, 29615-29619. doi: $10.1074 / \mathrm{jbc}$.R800019200

Tong, M., Arora, K., White, M. M., and Nichols, R. A. (2011). Role of key aromatic residues in the ligand-binding domain of $\alpha 7$ nicotinic receptors in the agonist action of $\beta$-amyloid. J. Biol. Chem. 286, 34373-34381. doi: 10.1074/jbc.M111.241299

Turner, P. R., O'Connor, K., Tate, W. P., and Abraham, W. C. (2003). Roles of amyloid precursor protein and its fragments in regulating neural activity, plasticity and memory. Prog. Neurobiol. 70, 1-32. doi: 10.1016/S0301-0082(03)00089-3

Tyan, S. H., Shih, A. Y., Walsh, J. J., Maruyama, H., Sarsoza, F., Ku, L., et al. (2012). Amyloid precursor protein (APP) regulates synaptic structure and function. Mol. Cell. Neurosci. 51, 43-52. doi: 10.1016/j.mcn.2012.07.009

van der Kant, R., and Goldstein, L. S. (2015). Cellular functions of the amyloid precursor protein from development to dementia. Dev. Cell. 32, 502-515. doi: 10.1016/j.devcel.2015.01.022

Vnencak, M., Paul, M. H., Hick, M., Schwarzacher, S. W., Del Turco, D., Muller, U. C., et al. (2015). Deletion of the amyloid precursor-like protein 1 (APLP1) enhances excitatory synaptic transmission, reduces network inhibition but does not impair synaptic plasticity in the mouse dentate gyrus. J. Comp. Neurol. 523, 1717-1729. doi: 10.1002/cne. 23766

Volianskis, A., and Jensen, M. S. (2003). Transient and sustained types of longterm potentiation in the CA1 area of the rat hippocampus. J. Physiol. 550( $\mathrm{Pt} 2)$, 459-492. doi: 10.1113/jphysiol.2003.044214

von Koch, C. S., Zheng, H., Chen, H., Trumbauer, M., Thinakaran, G., van der Ploeg, L. H., et al. (1997). Generation of APLP2 KO mice and early postnatal lethality in APLP2/APP double KO mice. Neurobiol. Aging 18, 661-669. doi: 10.1016/S0197-4580(97)00151-6

Walsh, D. M., Minogue, A. M., Sala Frigerio, C., Fadeeva, J. V., Wasco, W., and Selkoe, D. J. (2007). The APP family of proteins: similarities and differences. Biochem. Soc. Trans. 35(Pt 2), 416-420. doi: 10.1042/BST0350416

Walter, J., and Haass, C. (2000). Posttranslational modifications of amyloid precursor protein: ectodomain phosphorylation and sulfation. Methods Mol. Med. 32, 149-168. doi: 10.1385/1-59259-195-7:149.

Wang, B., Wang, Z., Sun, L., Yang, L., Li, H., Cole, A. L., et al. (2014). The amyloid precursor protein controls adult hippocampal neurogenesis through GABAergic interneurons. J. Neurosci. 34, 13314-13325. doi: 10.1523/jneurosci.2848-14.2014

Wang, H., Megill, A., He, K., Kirkwood, A., and Lee, H. K. (2012). Consequences of inhibiting amyloid precursor protein processing enzymes on synaptic function and plasticity. Neural Plast. 2012:272374. doi: 10.1155/2012/272374

Wang, P., Yang, G., Mosier, D. R., Chang, P., Zaidi, T., Gong, Y. D., et al. (2005). Defective neuromuscular synapses in mice lacking amyloid precursor protein (APP) and APP-Like protein 2. J. Neurosci. 25, 1219-1225. doi: 10.1523/JNEUROSCI.4660-04.2005

Wang, Z., Yang, L., and Zheng, H. (2012). Role of APP and $\mathrm{A} \alpha$ in synaptic physiology. Curr. Alzheimer Res. 9, 217-226. doi: $10.2174 / 156720512799361691$

Wasco, W., Gurubhagavatula, S., Paradis, M. D., Romano, D. M., Sisodia, S. S., Hyman, B. T., et al. (1993). Isolation and characterization of APLP2 encoding a homologue of the Alzheimer's associated amyloid $\beta$ protein precursor. Nat. Genet. 5, 95-100. doi: 10.1038/ng0993-95

Weyer, S. W., Klevanski, M., Delekate, A., Voikar, V., Aydin, D., Hick, M., et al. (2011). APP and APLP2 are essential at PNS and CNS synapses for transmission, spatial learning and LTP. EMBO J. 30, 2266-2280. doi: 10.1038/emboj.2011.119

Weyer, S. W., Zagrebelsky, M., Herrmann, U., Hick, M., Ganss, L., Gobbert, J., et al. (2014). Comparative analysis of single and combined APP/APLP knockouts reveals reduced spine density in APP-KO mice that is prevented by APPs $\alpha$ expression. Acta Neuropathol. Commun. 2:36. doi: 10.1186/2051-5960-2-36

Willem, M., Tahirovic, S., Busche, M. A., Ovsepian, S. V., Chafai, M., Kootar, S., et al. (2015). eta-Secretase processing of APP inhibits neuronal activity in the hippocampus. Nature 526, 443-447. doi: 10.1038/nature14864

Yang, L., Wang, Z., Wang, B., Justice, N. J., and Zheng, H. (2009). Amyloid precursor protein regulates Cav1.2 L-type calcium channel levels and function 
to influence GABAergic short-term plasticity. J. Neurosci. 29, 15660-15668. doi: 10.1523/JNEUROSCI.4104-09.2009

Yoshikai, S., Sasaki, H., Doh-ura, K., Furuya, H., and Sakaki, Y. (1990). Genomic organization of the human amyloid $\beta$-protein precursor gene. Gene 87, 257-263. doi: 10.1016/0378-1119(90)90310-N

Zhang, X., Zhong, W., Brankack, J., Weyer, S. W., Müller, U. C., Tort, A. B., et al. (2016). Impaired theta- $\gamma$ coupling in APP-deficient mice. Sci. Rep. 6:21948. doi: $10.1038 /$ srep 21948

Zou, C., Crux, S., Marinesco, S., Montagna, E., Sgobio, C., Shi, Y., et al. (2016). Amyloid precursor protein maintains constitutive and adaptive plasticity of dendritic spines in adult brain by regulating Dserine homeostasis. EMBO J. 35, 2213-2222. doi: 10.15252/embj.2016 94085
Zucker, R. S., and Regehr, W. G. (2002). Short-term synaptic plasticity. Annu. Rev. Physiol. 64, 355-405. doi: 10.1146/annurev.physiol.64.092501.114547

Conflict of Interest Statement: The authors declare that the research was conducted in the absence of any commercial or financial relationships that could be construed as a potential conflict of interest.

Copyright (๑) 2017 Ludewig and Korte. This is an open-access article distributed under the terms of the Creative Commons Attribution License (CC BY). The use, distribution or reproduction in other forums is permitted, provided the original author(s) or licensor are credited and that the original publication in this journal is cited, in accordance with accepted academic practice. No use, distribution or reproduction is permitted which does not comply with these terms. 